\section{$\underset{\substack{\text { hommes } \\ \text { \& migrations }}}{ }$}

\section{Hommes \& migrations}

Revue française de référence sur les dynamiques

migratoires

$1314 \mid 2016$

Migrations chinoises et générations

\title{
Jean-Paul Mari, Bateaux ivres
}

Paris, Lattès, 2015, 279 p., $19 €$

\section{Mustapha Harzoune}

\section{Q OpenEdition \\ 1 Journals}

\section{Édition électronique}

URL : http://journals.openedition.org/hommesmigrations/3680

DOI : 10.4000/hommesmigrations.3680

ISSN : 2262-3353

\section{Éditeur}

Musée national de l'histoire de l'immigration

\section{Édition imprimée}

Date de publication : 1 avril 2016

Pagination : 177-178

ISBN : 978-2-919040-35-3

ISSN : $1142-852 X$

\section{Référence électronique}

Mustapha Harzoune, « Jean-Paul Mari, Bateaux ivres », Hommes \& migrations [En ligne], 1314 | 2016, mis en ligne le 19 septembre 2016, consulté le 24 septembre 2020. URL : http://

journals.openedition.org/hommesmigrations/3680; DOI : https://doi.org/10.4000/ hommesmigrations.3680 
ensemble rabaissé ì une déclaration d'allégeance. En se gargarisant de la réussite de "ses" "bons immigrés", la société refoule les sacrifices, les frus trations, la désintégration des corps et des âmes. Ceux dece père venu avec sa famille se perdre au Mans. Malgréson statut de médecin, les Bui restaient "les immigrés dans cette coterie de notables". "Nous avons été de "bons immigrés"', faisant même semblant d'être français. "Pour nous intégrer, nous nous sommes désintégrés". "L'exil brise les pères", écrit Boan Bui, à coups de culpabilité pour eeux restés au pays et par un sentiment de "trahison" ì voir ses enfants "déjì passés de l'autre côté".

tauteure, qui voulait "tant être fran caise" - au point d'être aveugle aux siens-, ne se départira pas d'un sen

\section{Jean-Paul Mari}

\section{Bateaux ivres}

Paris, Lattès 2015, 279 pages, $19 €$

Sur ces "migrants" qui osent un "grand saut dans le vide", il est de bon ton de verser des larmes de crocodile pour mieux détourner le regard - Mme Merkel exceptée. Avec force et précision, Jean Paul Mari revient ici sur ces tragiques et modernes odyssées. II apporte même du neuf. Ainsi, s'il fallait une seule raison de lire ce livre, c'est au chapitre consacré à Lampedusa qu'il faudrait s'arrêter. Halo de lumière au milieu de timent d'imposture, de n'être jamais à sa place. Le jour où, pour un acte de naissance elle doit prouver sa qua lité de française, elle se sent rejetée"tout à coup je n'étais plus dans le bon eamp". Suspecte, il lui faut produire-le eertificat de naturalisation du père. Ses recherches la conduisent ì dénicher devieux documents et photos, des rapports de police aussi. Elle découvre des secrets insoupçonnables que des eouches épaisses de silence, recumu lées depuis deux générations, ne-sont pas parvenues ì eacher. Mais "il n'y aucune honte à avoir. Rien à cacher. Per sonne ne perdra la face". "La meravalera tout", écrit elle ì sa mère, "mon idole". Un livre tendre, écrit avec élégance-et pudeur. Ineroyablement courageux!

Austaphat Harzoune

pages sombres, il rappelle les règles qui font que l'humanité peut se prévaloir de ce titre, ébauche moins une politique qu'une ligne de conduite, digne, nourrie d'impératif moral et d'intelligence politique.

Car la question migratoire renvoie au courage, à l'hospitalité, à la solidarité. Les "Justes de Lampedusa" sont le boulanger qui baisse rideau pour aller porter secours, Costantino le maçon, Franscisco le menuisier, Massimo l'électricien, Giacomo le pêcheur ou Giusi Nicolini la maire de Lampedusa. Rien n'est facile! Mais ces Justes fixent la seule attitude possible pour agir sans forligner. Ils tissent les contours d'une politique plus efficace et plus humaine que le chacun pour soi européen et 


\section{LIVRES}

son vide assassin. Idem en Grèce - à Mytilène ou Lesbos - où "la crise a tué un pays, pas les individus" ou à Acquaformosa, ce village de Calabre, "ressuscité" grâce à l'accueil de réfugiés. Des réfugiés, pas des clandestins, qui "ont le droit - le droit, pas la charité - de trouver asile dans le pays d'Europe où ils s'exilent." D'Athènes à Ceuta, du Sinaï à Calais, Jean-Paul Mari montre les conséquences de la (non) politique de l'Europe-forteresse. II décrit les indignités des arrangements, avec l'ex-ami Khadafi par exemple. L'Italie de Berlusconi et l'Europe s'accommodaient alors de l'horreur des camps de rétention libyens. Aujourd'hui, une autre traite négrière, à la couleur de l'islam, se poursuit, sauvagement, en Libye ou en Égypte.

Ce livre, à la fois reportage et scénarisation, raconte la vie de ceux dont on cache les visages et les souffrances derrière des mots - "exilés", "sans-papiers" ou “infiltrés" (Israël). Ces êtres de chair et de sang se nomment Robiel, l'Érythréen ; Cédric, le Camerounais défenestré par la police marocaine ; Zachiel, l'imam afghan qui refuse de "pousser les gens à s'entretuer"; Fassi, le gamin de Guinée qui rêve de foot ; Rahwa, l'Érythréenne laissée pour morte dans une "maison de torture" au Sinaï ; Salomon, un des cinq miraculés d'une embarcation de plastique qui a dérivé pendant 23 jours... Et "l'essentiel" n'est pas la guerre, les persécutions ou la faim : "On peut survivre et même vivre dans la plupart des pays d'Afrique, du Moyen-Orient et d'Asie. (...) Ils savent comment est leur vie et comment elle va se terminer. Tout est déjà tracé, sans espoir de changement. Pour changer le destin, ne reste plus qu'à tout briser, partir, ouvrir le champ du possible même s'il peut mener à l'enfer. Et ils partent (...) poser une pierre dans le jardin d'un autre monde." M. H.

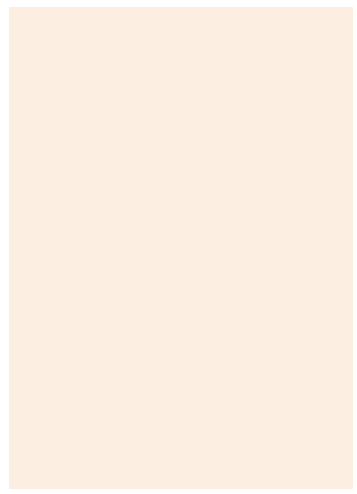

Khaled-Osman

tacolombe

et le moineau

ta Roque d'Anthéron, vents d'ailleurs, 2016, 173 pages, $20 €$

Samir est réveillé par un appel qui vient de ta Place Tahrir au Caire. Unsoignant lui apprend qu'on a trouvé son

Auméro de téléphone sur un homme quivient d'être prisen charge. Avant de sombrer dans le coma, l'inconnu a pu articuler: "qu'il vienne mais avec elle".
Samir,prof d'histoire de civilisation arabe ì Paris, qui a coupé les ponts avec son passé, comprend qu'il s'agit d'Hicham, son frèrejumeau,lequelluidemande de revenir avec Lamia, son ex petite amie. Eommence alors l'enquête pour retrou verlajeune femme..

Eettetramesemble n'êtrequ'un subter fuge littéraire pourentretenir le lecteur de thèmes d'importancesurl'exilet sur ta culture, la mémoire ou le devenir du monde "arabe". II y a comme un éche uux Considérations surle malheur arabe de Samir Kassir (Actes Sud, 2008). En érudit et éminent traducteur, l'auteur fait dialoguer les siècles et les textes, 